
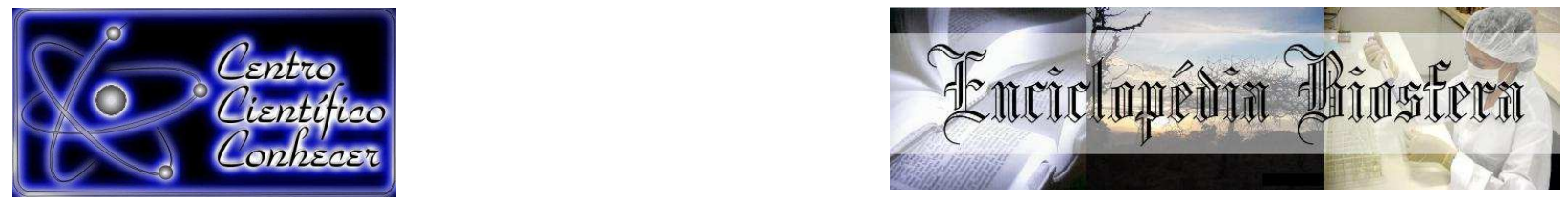

\title{
DINÂMICA DO USO E COBERTURA DO SOLO ENTRE OS ANOS DE 2004 E 2014 PARA O MUNICÍPIO DE CAPITÃO POÇO, PARÁ
}

\author{
Nívia Cristina Vieira Rocha
}

Mestra em Ciências Ambientais pela Universidade Federal do Pará. (niviavieira.ciamb@gmail.com) Belém-Brasil.

Recebido em: 02/10/2017 - Aprovado em: 21/11/2017 - Publicado em: 05/12/2017

DOI: 10.18677/EnciBio_2017B23

\begin{abstract}
RESUMO
O município de Capitão Poço se destaca no estado do Pará por apresentar características voltadas a atividades agropecuárias, as quais são principais agentes para a ocorrência de desmatamento nesta área. Este estudo teve por objetivo analisar a dinâmica do uso e cobertura do solo para os anos de 2004 e 2014 no município, utilizando dados do projeto TerraClass, os quais foram tratados e inseridos no banco de dados do software ArcGis 10.2 para a elaboração de mapas e interpretação das informações. Foi constatada que a classe de pasto limpo é considerada a matriz do município por apresentar uma maior representatividade em ambos os anos, principalmente em 2014 onde foi mapeado o dobro de área identificada em 2004 e uma significativa redução nas áreas de floresta primária enquanto a vegetação secundária apresentou um pequeno aumento. A análise da dinâmica do uso e cobertura do solo mostrou a importância de haver a conservação dos recursos florestais, além da elaboração de estratégias capazes de melhorar a qualidade de vida da população e equilíbrio ambiental.
\end{abstract}

PALAVRAS-CHAVE: Amazônia oriental, análise espaço-tempora, terraclass.

\section{DYNAMICS OF LAND USE AND LAND COVER BETWEEN THE YEARS 2004 AND 2014 IN CAPITÃO POÇO MUNICIPALITY, PARÁ}

\begin{abstract}
The municipality of Capitão Poço stands out in the state of Pará because it presents characteristics related to agricultural activities, which are the main agents for the occurrence of deforestation in this area. This study aimed to analyze the dynamics of land use and land cover for the years 2004 and 2014 in the municipality, using data from the TerraClass project, which were treated and inserted into the ArcGis 10.2 software database for mapping and interpretation of information. It was verified that the class of herbaceous pasture is considered the matrix of the municipality because it presents a greater representativeness in both years, mainly in 2014 where it was mapped double the area identified in 2004 and a significant reduction in the areas of forested areas while the secondary vegetation presented a small increase. The analysis of the dynamics of land use and land cover showed the importance of conserving forest resources, as well as the elaboration of strategies capable of improving the quality of life of the population and environmental balance.
\end{abstract}

KEYWORDS: Eastern Amazon. Spatial-temporal analysis. TerraClass. 


\section{INTRODUÇÃO}

O acelerado processo de crescimento populacional, principalmente de áreas urbanas e industriais, gera um aumento em demandas como água e alimentos, as quais são dependentes do sistema de produção (NASCIMENTO; FERNANDES, 2017), ocasionando assim, diversas pressões sobre o território, inclusive 0 crescimento do número de áreas voltadas para as atividades da indústria agropecuária (SILVA et al., 2013), gerando também impactos ambientais (WENCESLAU; ROCHA, 2012).

Na região Amazônica, o processo uso do solo foi intensificado entre os anos de 1950 e 1960 (BECKER, 2004), a partir do plano de integração nacional (PIN), o qual visava à integração do território nacional por meio de rodovias promovendo a migração para a Amazônia (MARGARIT, 2013). As estratégias do governo e de empresas em relação à Amazônia voltam-se para a agroindústria, sendo que a soja, carne, minérios, suco de laranja, petróleo e celulose, são produtos que mais são exportados e produzidos no Brasil, e no ano de 2010, estes três primeiros eram, em sua maioria, produzidos na Amazônia (CASTRO, 2012).

A identificação e classificação dos processos de uso e cobertura do solo são necessárias para o conhecimento dos ambientes e também para o desenvolvimento de métodos capazes de adquirir informações e atualização das mesmas (VAEZA et al., 2010). É um tema que está sendo considerado como "delicado", pois, leva em consideração, diversos interesses e pode provocar alterações em processos socioeconômicos e ambientais, além de expressar um componente do conjunto de atividades de uma sociedade.

Os padrões de uso e cobertura do solo podem influenciar direta ou indiretamente na qualidade da água, fluxo de fauna, além de alterar áreas, ocasionando perda de habitat e da biodiversidade (ROMÃO et al., 2017). Esses dados têm provocado interesse de todos os atores da sociedade, já que os mesmos são resultados da aplicação de técnicas de monitoramento de áreas, passiveis de impactos ambientais sociais e econômicos, além de possibilitar o acompanhamento, a curto e longo prazo, do desenvolvimento destas em diferentes escalas: local, regional e global (LEITE; ROSA, 2012; SILVA, 2015).

De acordo com esse histórico, foram surgindo alguns projetos e programas os quais possibilitaram o monitoramento das áreas no intuito de entender como funciona a dinâmica do uso e cobertura do solo da Amazônia brasileira, sendo que o projeto TerraClass, o qual é desenvolvido pelo Instituto Nacional de Pesquisas Espaciais (INPE) em parceria com a Empresa Brasileira de Pesquisa Agropecuária (Embrapa), é considerado um dos mais disseminados no país, pois o mesmo disponibiliza produtos referente as áreas florestadas e desflorestadas desta região (ALMEIDA et al., 2016).

Nesse contexto, enquadra-se o município de Capitão Poço, localizado no nordeste do estado do Pará, o qual é considerado um dos grandes produtores de laranja e pimenta do reino do estado, além de possuir uma vasta quantidade de áreas voltadas à criação de gado (ALVES et al., 2015). Sendo assim, o objetivo desta pesquisa é analisar o processo de uso e cobertura do solo do município e a sua dinâmica em um intervalo de dez anos. 


\section{Área de estudo}

\section{MATERIAL E MÉTODOS}

O município de Capitão Poço está localizado na Amazônia Oriental, mais especificamente no nordeste do estado do Pará apresentando cerca de $2.900 \mathrm{~km}^{2} \mathrm{e}$ aproximadamente 52.800 habitantes, seguindo as coordenadas geográficas de 01⒋4'47'S e 4703'57'W (ALVES et al., 2015), na área de influência direta da bacia do rio Guamá, cerca de $200 \mathrm{~km}$ de distância da capital do estado, Belém. Este município faz fronteira com os municípios de Ourém ao norte; Santa Luzia do Pará e Garrafão do Norte à leste; Nova esperança do Piriá e Ipixuna do Pará ao Sul; e Aurora do Pará, Mãe do Rio e Irituia à oeste (Figura 1).

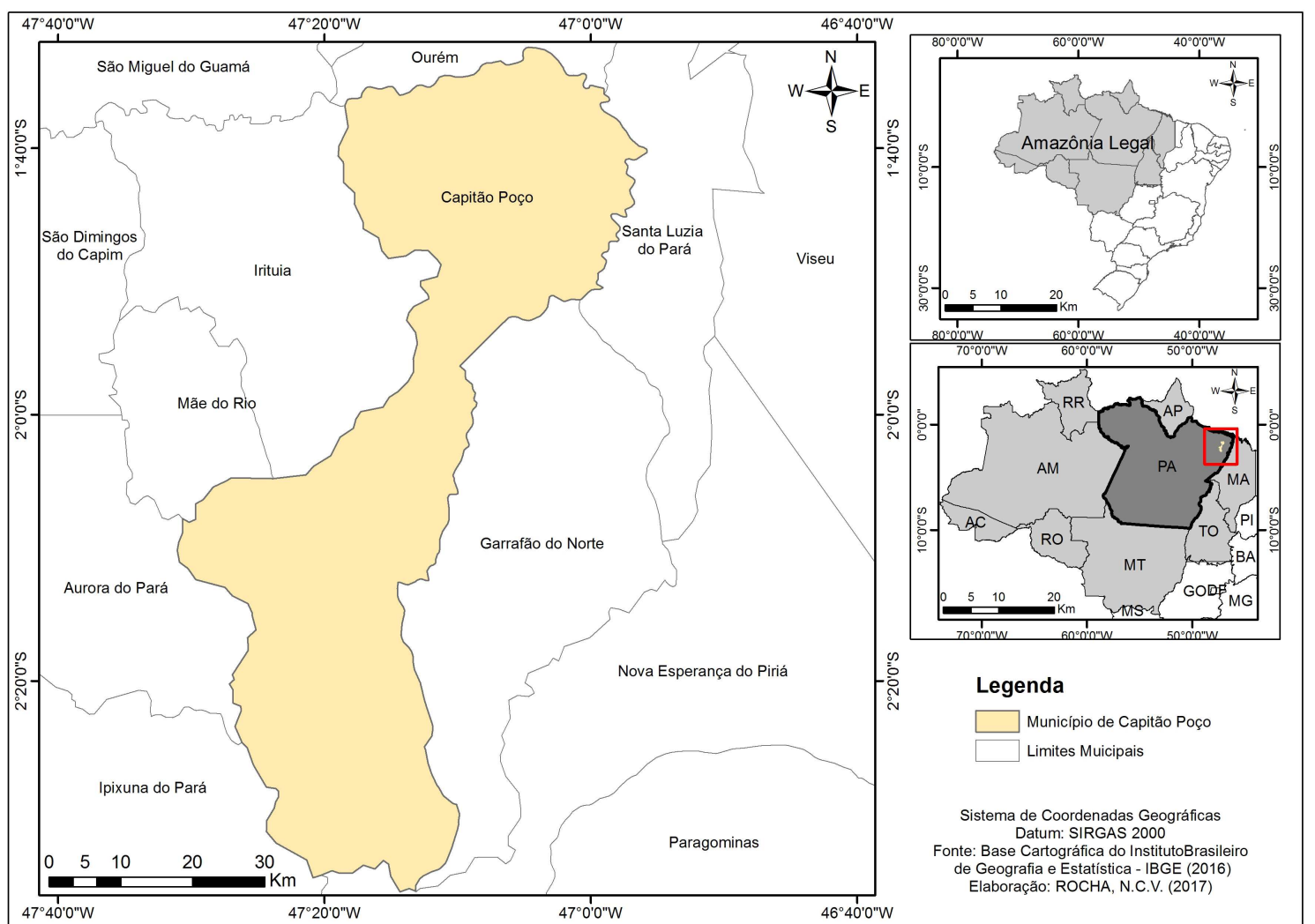

FIGURA 1 - Localização do município de Capitão Poço no estado do Pará.

Fonte: Autora (2017).

O surgimento do município está vinculado ao período de integração da região amazônica ao restante do território nacional, com a instalação de rodovias que permitiram a exploração de novos territórios. No início da década de 1960, Capitão Poço ainda era considerado como uma das várias vilas que faziam parte do município de Ourém, mas em 29 de dezembro de 1961 ocorreu a emancipação do mesmo por meio da Lei Estadual № 2460 (IBGE, 2017).

\section{Procedimentos Metodológicos}

A delimitação do município de Capitão Poço se deu de acordo com a base de dados cartográficos digital do Instituto Brasileiro de Geografia e Estatística - IBGE, por meio do arquivo vetorial em escala de 1:250.000 (IBGE, 2016). Para a análise dos dados de uso e cobertura do solo, foram utilizados os dados do projeto TerraClass, do Instituto Nacional de Pesquisas Espaciais, gerado a partir do satélite Landsat (sensor TM), com 30 metros de resolução espacial (INPE; EMBRAPA, 
2013), levando em consideração um intervalo de 10 anos ao selecionar os anos de 2004 e 2014.

No âmbito do projeto TerraClass foram identificadas 15 classes temáticas: área não observada, área urbana, agricultura anual, desflorestamento, floresta, hidrografia, mineração, mosaico de ocupações, não floresta, outros, pasto com solo exposto, pasto limpo, pasto sujo, regeneração com pasto e vegetação secundária (quadro 1).

QUADRO 1 - Classes de uso e cobertura da terra para o município de Capitão Poço.

\begin{tabular}{|c|c|}
\hline Classe & Características \\
\hline $\begin{array}{l}\text { Área não } \\
\text { observada }\end{array}$ & $\begin{array}{l}\text { Áreas que tiveram sua interpretação impossibilitada pela ocorrência de } \\
\text { nuvens ou sombra das nuvens, no instante de passagem do satélite para } \\
\text { aquisição de imagens, além de áreas queimadas recentemente. }\end{array}$ \\
\hline Área urbana & $\begin{array}{l}\text { São manchas urbanas provenientes da concentração da população, } \\
\text { formando lugarejos, vilas ou cidades as quais apresentam uma } \\
\text { infraestrutura diferenciada da área rural apresentando adensamento de } \\
\text { arruamentos, casas, prédios e outros equipamentos públicos. }\end{array}$ \\
\hline $\begin{array}{l}\text { Agricultura } \\
\text { anual }\end{array}$ & $\begin{array}{l}\text { Áreas extensas com predomínio de culturas de ciclo anual, sobretudo de } \\
\text { grãos, utilizando padrões tecnológicos elevados. }\end{array}$ \\
\hline $\begin{array}{l}\text { Desflorestam } \\
\text { ento }\end{array}$ & Área de floresta recentemente suprimida. \\
\hline Floresta & Área de floresta primária não alterada. \\
\hline Hidrografia & Corpos d'água, rios, lagos, riachos e lagoas. \\
\hline Mineração & $\begin{array}{l}\text { Áreas de extração mineral com a presença de clareiras e solos expostos, } \\
\text { envolvendo desflorestamentos nas proximidades de águas superficiais. }\end{array}$ \\
\hline $\begin{array}{l}\text { Mosaico de } \\
\text { ocupações }\end{array}$ & $\begin{array}{l}\text { Áreas representadas por uma associação de diversas modalidades de uso } \\
\text { da terra e que devido à resolução espacial das imagens de satélite não é } \\
\text { possível uma discriminação entre seus componentes. A agricultura familiar } \\
\text { é realizada de forma conjugada a pastagens para criação tradicional de } \\
\text { gado. }\end{array}$ \\
\hline Não floresta & $\begin{array}{l}\text { Areas com vegetação característica de campos naturais (pioneiras } \\
\text { herbáceas e/ou arbustiva). }\end{array}$ \\
\hline Outros & $\begin{array}{l}\text { Áreas que não se enquadram nas chaves de classificação e apresentam } \\
\text { padrão de cobertura diferenciada de todas as classes do projeto, tais como } \\
\text { afloramentos rochosos, praias fluviais e bancos de areia. }\end{array}$ \\
\hline $\begin{array}{l}\text { Pasto com } \\
\text { solo exposto }\end{array}$ & $\begin{array}{l}\text { Áreas que, após o corte raso da floresta e o desenvolvimento de alguma } \\
\text { atividade agropastoril, apresentam uma cobertura de pelo menos } 50 \% \text { de } \\
\text { solo exposto. }\end{array}$ \\
\hline Pasto limpo & $\begin{array}{l}\text { Áreas de pastagem em processo produtivo com predomínio de vegetação } \\
\text { herbácea, e cobertura de espécies de gramíneas entre } 90 \text { e } 100 \% \text {. }\end{array}$ \\
\hline Pasto sujo & $\begin{array}{l}\text { Áreas de pastagem em processo produtivo com predomínio da vegetação } \\
\text { herbácea e cobertura de espécies de gramíneas entre } 50 \text { e } 80 \% \text {, associado } \\
\text { à presença de vegetação arbustiva esparsa com cobertura entre } 20 \text { e } 50 \% \text {. }\end{array}$ \\
\hline $\begin{array}{l}\text { Regeneração } \\
\text { com pasto }\end{array}$ & $\begin{array}{l}\text { Áreas que, após o corte raso da vegetação natural e o desenvolvimento de } \\
\text { alguma atividade agropastoril, encontram-se no início do processo de } \\
\text { regeneração da vegetação nativa, apresentando dominância de espécies } \\
\text { arbustivas e pioneiras. }\end{array}$ \\
\hline $\begin{array}{l}\text { Vegetação } \\
\text { secundária }\end{array}$ & $\begin{array}{l}\text { Áreas que, após a supressão total da vegetação florestal, encontra-se em } \\
\text { processo avançado de regeneração da vegetação arbustiva e/ou arbórea } \\
\text { ou que foram utilizadas para a prática de silvicultura ou agricultura } \\
\text { permanente com uso de espécies nativas ou exóticas. }\end{array}$ \\
\hline
\end{tabular}

Fonte: adaptado de INPE e EMBRAPA (2013). 
O processamento dos dados se deu por meio do software ArcGIS 10.2, onde foram realizados o recorte dos dados do TerraClass dentro dos limites do município e verificação da área de cada classe de estudo, além da elaboração dos mapas de uso e cobertura do solo, segundo a projeção dos dados vetoriais para o sistema de projeção cartográfica Universal Transversa de Mercator - UTM, SIRGAS 2000 nas zonas 22 e 23.

\section{RESULTADOS E DISCUSSÃO}

A partir da análise dos dados, pode-se observar que as áreas que apresentam maior representatividade no município de 2004 e 2014, ou seja, representam a matriz de Capitão Poço, são as áreas de pasto limpo que possuem, neste último ano, mais de $50 \%$ do território, tendo um acréscimo de $52,65 \%$ de seus limites, passando de $69.176,11$ ha para $146.091,11$ ha, como pode ser observado na tabela 1. Esse resultado demonstra o forte crescimento da atividade pecuária nos últimos anos assim como tem ocorrido em toda a região Amazônica, a qual é considerada uma das maiores produtoras de carne do país (VAZ, 2012).

TABELA 1 - Área (em hectares) ocupada pelas classes de uso e cobertura do solo no município de Capitão Poço para os anos de 2004 e 2014.

\begin{tabular}{lcccc}
\hline \multirow{2}{*}{ Classes } & \multicolumn{2}{c}{ Área em 2004 } & \multicolumn{2}{c}{ Área em 2014 } \\
\cline { 2 - 5 } & (ha) & (\%) & (ha) & (\%) \\
\hline Área não observada & $31.418,57$ & 10,84 & $8.115,38$ & 2,80 \\
Área urbana & 296,49 & 0,10 & $1.663,78$ & 0,57 \\
Agricultura anual & 0,00 & 0,00 & 63,32 & 0,02 \\
Desflorestamento & $2.882,45$ & 0,99 & 50,63 & 0,02 \\
Floresta & $41.371,59$ & 14,27 & $31.550,17$ & 10,89 \\
Hidrografia & 348,95 & 0,12 & 348,95 & 0,12 \\
Mineração & 0,00 & 0,00 & 354,58 & 0,12 \\
Mosaico de ocupações & $21.416,81$ & 7,39 & $7.957,76$ & 2,75 \\
Não floresta & 172,60 & 0,06 & 172,60 & 0,06 \\
Outros & 696,23 & 0,24 & 791,28 & 0,27 \\
Pasto com solo exposto & 15,66 & 0,01 & 0,00 & 0,00 \\
Pasto Limpo & $69.176,11$ & 23,87 & $146.091,11$ & 50,40 \\
Pasto Sujo & $35.407,77$ & 12,22 & $23.191,04$ & 8,00 \\
Regeneração com pasto & $46.296,38$ & 15,97 & $15.426,51$ & 5,32 \\
Vegetação secundária & $40.342,94$ & 13,92 & $54.065,44$ & 18,65 \\
\hline Fonte: Autora (2017).
\end{tabular}

Fonte: Autora (2017).

Este avanço em relação à classe de pasto limpo, além de ser comprovado por meio dos dados quantitativos, também pode ser notado no mapa de uso e cobertura do solo para o município de Capitão Poço (Figura 2). Nele, pode-se observar uma grande homogeneidade e progressão desta em todo o território entre os anos analisados. Nota-se principalmente que esta classe substitui, em grande parte, as áreas referentes aos mosaicos de ocupações, pasto sujo e as áreas não observadas, fato ressaltado em vários segmentos do mapa, principalmente a sudoeste. 


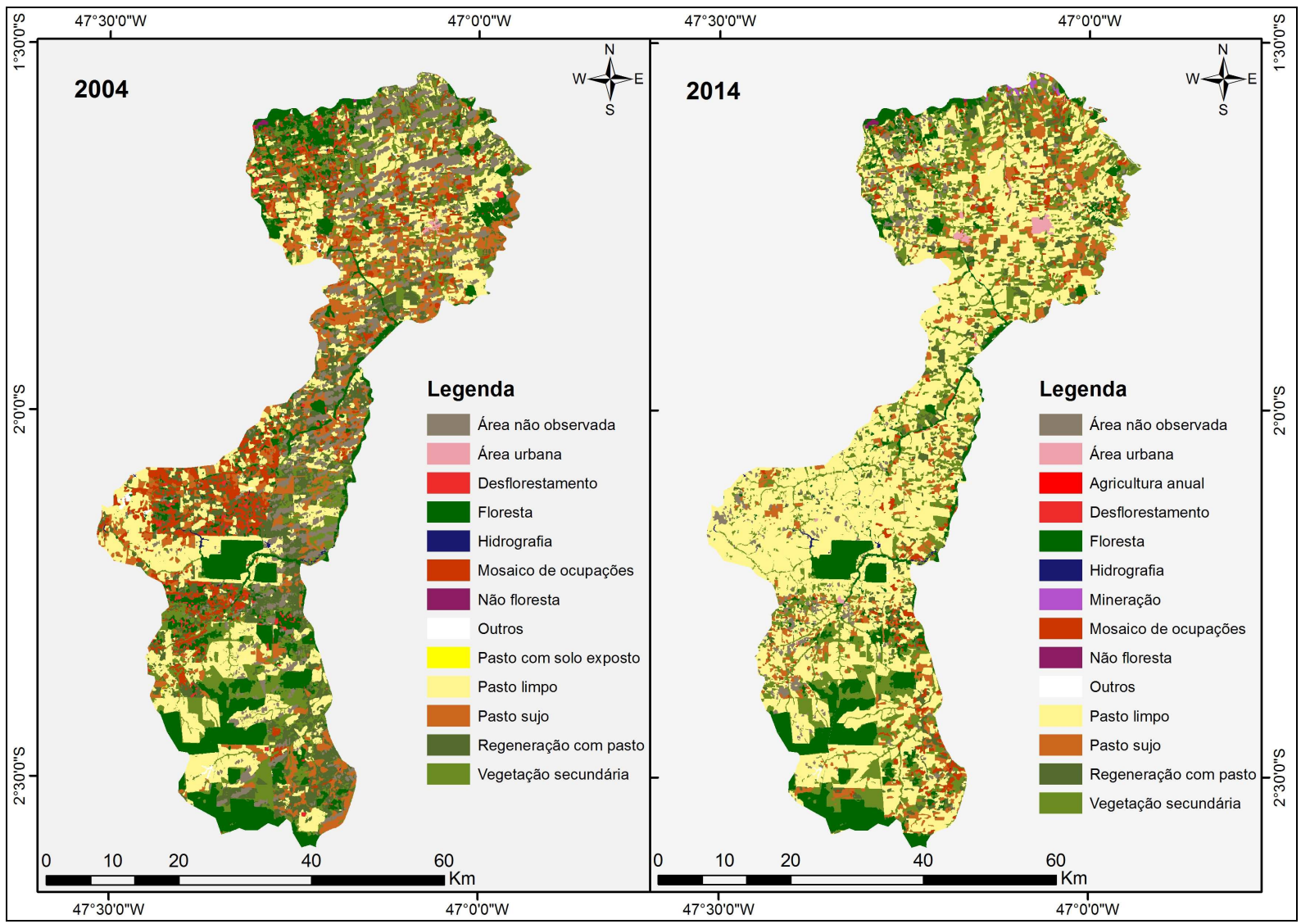

FIGURA 2 - Uso e cobertura do solo para o município de Capitão Poço nos anos de 2004 e 2014.

Fonte: Autora (2017).

Ainda se referindo a classes relacionadas a pastagem, tem-se o pasto com solo exposto, o qual apresenta uma representatividade muito pequena levando em consideração a área total do município, já que esta representa cerca de 0,01\% equivalendo a 15,66 ha para o ano de 2004, já no ano de 2014 estas áreas deixam de existir. Tal fato pode ser explicado de acordo com o período de crescimento e estabilidade das espécies de gramíneas, já que este tipo de classe representa as áreas com alguma atividade agropastoril, como o próprio preparo do solo para receber o plantio destas espécies que constituem uma pastagem (INPE; EMBRAPA, 2013).

Em relação ao pasto sujo, nota-se uma redução de área, levando em consideração os anos analisados, de 4,21\% em relação ao município e 34,50\% dentre seus limites, passando de $35.407,77$ ha para $23.191,04$ ha. O consumo das áreas de pastagem é realizado de maneira acelerada, sendo necessário o desencadeamento de técnicas de pousio, que é utilizada para preservar a terra e restabelecer os nutrientes da mesma, surgindo assim áreas de pasto sujo (CIRNE; SOUZA, 2014), prática muito adotada no agronegócio em todo o país. Porém, no caso de Capitão Poço, houve um processo inverso, sendo que em 2004 existiam mais áreas de pousio e em 2014 essas áreas voltaram a ser utilizadas para os seus devidos usos.

Além dessas áreas, as que representam as de regeneração com pasto também obtiveram uma redução ao longo dos anos, passando de 46.296,38 ha para $15.426,51$ ha, uma diminuição de mais de $10 \%$ de representatividade no município e 
de mais de $66 \%$ perdas de área da classe. O investimento em áreas relacionadas a pastagem, possibilita um aumento na conversão de áreas florestais em áreas de pastagem, situação que pode ocasionar mudanças no clima local, já que a vegetação arbórea apresenta maior as trocas de água e energia com a atmosfera do que a vegetação rasteira (BUIDES et al., 2012), além de também ocasionar alterações no solo, na biota, em recursos hídricos, dentre outros, influenciando assim no equilíbrio do ecossistema (SILVA et al., 2013).

Para a classe floresta, apesar de ser a terceira classe mais representativa do município de Capitão Poço para o ano de 2014, apresentando cerca de $10 \%$ de espacialização, teve uma redução de 23,74\% durante os dez anos de análise, passando de $41.371,59$ ha para $31.550,17$ ha. Tal fato demonstra a grande quantidade de supressão da vegetação nativa e primária para transformá-las em outros tipos de uso, como por exemplo, atividades voltadas para a agropecuária e exploração mineral, o que provoca um desequilíbrio no ambiente (CALANDINO et al., 2012). Segundo IBGE (2010), cerca de $20 \%$ das áreas de floresta primária na Amazônia brasileira já estão desmatadas, dado preocupante mesmo depois da implementação de políticas que visam a redução do desmatamento na região (FERREIRA; COELHO, 2015).

Além da classe de floresta que é representada como vegetação arbórea as áreas de vegetação secundária também têm estas características. Esta classe obteve um aumento considerável de 25,38\% em seus limites entre os anos de 2004 e 2014, passando a ter $54.065,44$ ha neste último, além de ser a segunda classe mais representativa do município com $18,65 \%$ de cobertura do mesmo. Este dado trás um aspecto positivo para o município, pois apresenta um avanço de áreas verdes, além do que a vegetação secundária, no estado do Pará, geralmente é oriunda de áreas de pastagens as quais perderam a sua produtividade e não estão mais em uso (ADAMI et al., 2015). Os efeitos negativos provocados pelo desflorestamento podem ser minimizados devido ao surgimento dessas novas áreas de vegetação além do restabelecer a conexão entre os fragmentos florestais existentes, contribuindo para a circulação de espécies faunísticas e manutenção da biodiversidade (ADAMI et al., 2010).

Outra explicação para o aumento das áreas referentes a vegetação secundária pode estar ligada ao fato de o município de Capitão Poço ser um dos principais produtores de laranja do estado do Pará, já que a característica de um cultivo deste não se enquadra a classe agricultura anual e a resposta capturada pelas imagens de satélite permita a interpretação de enquadramento nesta categoria.

As áreas de desflorestamento tiveram uma grande redução neste período de dez anos, sendo que de 2.882,45 ha em 2004 passou a ser 50,63 ha em 2014. Estes dados não comprovam a redução do desflorestamento em si, porém nota-se uma diminuição da sua intensidade, sendo que as áreas desflorestadas em 2004 se tornaram outros tipos de uso, como por exemplo, as pastagens, fato que também ocorrerá nos locais mapeados mais recentemente.

A agricultura anual é representada principalmente pelo cultivo de grãos, sendo que em 2004 não foi registrada nenhuma área referente a esta classe, mas em 2014 , surgiram 63,32 ha de plantio, tendo apenas $0,02 \%$ de representatividade no município em análise. A agricultura no município de Capitão Poço está muito ligada ao cultivo de laranja, mandioca, banana, feijão, pimenta do reino, milho, soja e arroz, sendo que os grãos, que representam esta classe analisada, apresentam um pequeno uso de área (IBGE, 2010). 
A classe referente a mineração também só se tornou presente no ano de 2014 , com uma área de 354,58 ha e $0,12 \%$ no município, o que significa o crescimento e surgimento de atividades mineradoras em diversas regiões da Amazônia (ROMÃO et al., 2017). Apesar da extração de minérios ferro, caulim, bauxita, dentre outros serem bem difundidos na região Amazônica, no município em análise, as principais atividades mineradoras presentes estão ligadas a extração de areia e piçarra que auxiliam na construção civil.

As áreas urbanas também apresentaram um crescimento de área, correspondendo a 82,18\%, expandindo de 296,49 ha em 2004 para 1.663,78 ha em 2014. Essa classe está representada pela sede municipal do município, além das suas vilas e comunidades rurais. Este fato se deu devido o crescimento populacional e demanda de qualidade de vida para esta população, que migra de lugares mais isolados em busca de melhorias de vida.

Além das áreas urbanas, a classe de mosaico de ocupações também apresentam habitações, porém, as mesmas estão ligadas a pequenas propriedades produtivas relacionadas a atividades agropastoris, já para Côrtes e Bueno (2014) apresentaram esta classe como o que se aproxima do processo de urbanização incipiente das áreas rurais. No município, nota-se uma redução considerável dessas áreas em cerca de $60 \%$ de sua área total e 4,64\% no município, sendo que em 2004 abrangia 21.416,81 ha e em 2014 passou a ter 7.957,76 ha, redução de pouco menos que um terço de território.

Dentre todas as classes analisada, duas apresentaram uma conservação de suas áreas, ou seja, não apresentaram alterações ao logo desses dez anos de análise, foram eles os espaços referentes a hidrografia e as não florestas sendo o primeiro representado por 348,95 ha e o segundo de 172,60 ha. É importante ressaltar que no município de Capitão Poço está localizada a nascente de um dos rios mais significativos para o nordeste paraense, que é o rio Guamá (SILVA, 2014). A preservação e conservação de áreas de hidrografia são de fundamental importância para que exista um equilíbrio hídrico na região, principalmente para a manutenção e suprimento das áreas de pastagem e agricultura, principais atividades econômicas do município.

A última classe a ser analisada é a que se refere às áreas não observadas, que são representadas pelas nuvens e sombras das nuvens. Esta classe não se enquadra em nenhum requisito de uso e ocupação do solo, porém, por apresentar uma significativa representação espacial, principalmente no ano de 2004, sua análise deve ser levada em consideração. No ano de 2004, esta classe recobriu $31.418,57$ ha, correspondendo a $10,84 \%$ do mapeamento do município, já em 2014, houve uma redução de $74,17 \%$ de representação espacial, passando a ter apenas $8.115,38$ ha. Esta informação indica que mais áreas de uso e cobertura foram encobertas por esta classe, dificultando a sua classificação de forma adequada, onde o último ano de análise apresentou melhor representatividade de suas classes mapeadas.

\section{CONCLUSÃO}

A análise do uso e cobertura do solo a partir da interpretação dos dados do projeto TerraClass sobre a área do município de Capitão Poço entre os anos de 2004 e 2014, foi de fundamental importância para a entender a dinâmica e transformações ocorridas ao longo destes anos. 
Houve um crescimento significativo para a classe de uso do solo pasto limpo, fazendo desta a sua matriz. Em contraposto a classe de floresta apresentou uma grande redução de área e a de vegetação secundária apresentou um pequeno crescimento, sendo que mediante a importância destas para a manutenção do equilíbrio no ecossistema, a gestão municipal deve elaborar estratégias as quais favoreçam esta cobertura vegetal e reduzindo os processos do desmatamento.

A dinâmica do uso e cobertura do solo no município foi de fundamental importância para que sejam realizadas tomadas de decisão capazes de fornecer um planejamento para organização do espaço, a qual contribua para o desenvolvimento sustentável do município, com um equilíbrio ambiental, econômico e social, visando a melhoria da qualidade de vida da população e sustentação do ambiente ali existente.

\section{REFERÊNCIAS}

ADAMI, M.; GOMES, A. R.; COUTINHO, A. C.; ESQUERDO, J. C. D. M.; ALMEIDA, C. A.; et al. Estimativa de área de vegetação secundária na Amazônia Legal Brasileira. Acta Amazonica, v.40, n.2, p.289-302, 2010. Disponível em: <http://dx.doi.org/10.1590/S0044-59672010000200007>. doi: 10.1590/S004459672010000200007

. Dinâmica do uso e cobertura da terra no estado do Pará entre os anos de 2008 a 2012. In: Simpósio Brasileiro de Sensoriamento Remoto 2015, João Pessoa/PB. Anais... João Pessoa/PB, 2015, v. 17, p. 7028-7035.

ALMEIDA, C. A.; COUTINHO, A. C.; ESQUERDO, J. C. D. M.; ADAMI, M. VENTURIERI, A.; et al. High spatial resolution land use and land cover mapping of the Brazilian Legal Amazon in 2008 using Landsat-5/TM and MODIS data. Acta Amazônica, v. 46, n. 3, p. 291-302, 2016. Disponível em: <http://dx.doi.org/10.1590/ 1809-4392201505504>. doi: 10.1590/1809-4392201505504

ALVES, J. D. N. A.; MOTA, F. F. A.; FERRAZ, Y. T.; JESUS, R. T. L.; OKUMURA, R. $S$. Evolução da produtividade de laranja e pimenta-do-reino no período de 20002012 no município de Capitão Poço, PA. Enciclopédia Biosfera, v. 11, n. 21, p. 1068-1077, 2015. Disponível em: <http://www.conhecer.org.br/enciclop/2015b/agrari as/evolucao\%20da\%20produtividade.pdf>.

BECKER, B. K. Amazônia: Geopolítica na virada do III milênio. Rio de Janeiro, Gramond, 2004, 172p.

BUIDES, M. S.; NOGUEIRA, J. S.; DALMAGRO, H. J.; MACHADO, N. G.; DANELICHEN, V. H. M.; et al. Mudança no microclima provocada pela conversão de uma floresta de cambará em pastagem no norte do Pantanal. Revista de Ciências Agro-Ambientais, v. 10, n. 1, p. 61-68, 2012. Disponível em: <http://www.unemat.br /revistas/rcaa/docs/vol10/ARTIGO_7_RCAA_v10n1a2012.pdf>.

CALANDINO, D.; WEHRMANN, M.; KOBLITZ, R. Contribuição dos assentamentos rurais no desmatamento da Amazônia: um olhar sobre o estado do Pará. Desenvolvimento e Meio Ambiente, v. 26, n.1, p. 161-170, 2012. Disponível em: <http://dx.doi.org/10.5380/dma.v26i0.26017>. doi: 10.5380/dma.v26i0.26017 
CASTRO, E. Expansão da fronteira, megaprojetos de infraestrutura e a integração Sul-Americana. Caderno CRH, v. 25, n. 64, p. 45-61, 2012. Disponível em: <http://dx.doi.org/10.1590/S0103-49792012000100004>. doi: 10.1590/S010349792012000100004

CIRNE, M. B.; SOUZA, A. G. S. M. Pousio: o que é e quais são os seus possíveis reflexos nas questões ambientais. Veredas do Direito, v. 11, n. 21, p. 75-106, 2014. Disponível em: <http://www.domhelder.edu.br/revista/index.php/veredas/article/viewF ile/311/400>.

CÔRTES, J. C.; BUENO, M. C. D. Integrando distribuição populacional e usocobertura da terra: testando novas abordagens metodológicas para a Amazônia. In: ENCONTRO NACIONAL DE ESTUDOS POPULACIONAIS, 2014, São Pedro/SP. Anais... São Pedro/SP, 2014, v. 19, p. 1-21.

FERREIRA, M. D. P.; COELHO, A. B. Desmatamento recente nos estados da Amazônia Legal: uma análise da contribuição dos preços agrícolas e das políticas governamentais. Revista de Economia e Sociologia Rural, v. 53, n. 1, p. 93-108, 2015. Disponível em: <http://dx.doi.org/10.1590/1234-56781806-9479005301005>. doi: 10.1590/1234-56781806-9479005301005

IBGE - Instituto Brasileiro de Geografia e Estatística. IBGE Cidades@. Disponível em: <http://cidades.ibge.gov.br/xtras/perfil.php?lang=\&codmun=150230\&search=par a|capitao-poco>. Acesso em: 19 set. 2017.

Base de dados cartográficos. Disponível em: <http://mapas.ibge.gov.br/ bases-e-referenciais/bases-cartograficas/malhas-digitais>. Acesso em: 19 dez. 2016.

Indicadores de Desenvolvimento Sustentável: Brasil 2010. Rio de Janeiro, RJ: [s.n.]. Disponível em: <http://www.ibge.gov.br/home/geociencias/recurso snaturais/ids/ids2010.pdf>. Acesso em: 01 set. 2017.

INPE; EMBRAPA. Uso e cobertura da terra nas áreas desflorestadas da Amazônia Legal: TerraClass 2008. (Org.) Alexandre Camargo Coutinho; Cláudio Almeida; Adriano Venturieri; Júlio César Dalla Mora Esquerdo; Maurício Silva. Brasília, DF: Embrapa; Belém: INPE 2013.

LEITE, E. F.; ROSA, R. Análise do uso, ocupação e cobertura da terra na bacia hidrográfica do rio Formiga, Tocantins. Revista Eletrônica de Geografia, v. 4, n. 12, p. 90-106, 2012. Disponível em: <http://www.observatorium.ig.ufu.br/pdfs/4edicao/n1 2/05.pdf>.

MARGARIT, E. O processo de ocupação do espaço ao longo da BR-163: uma leitura a partir do planejamento regional estratégico da Amazônia durante o governo militar. Geografia em Questão, v. 6, n. 1, p. 12-31, 2013. Disponível em: <http://erevista.unioeste.br/index.php/geoemquestao/article/view/6634/5786>. 
NASCIMENTO, T. V.; FERNANDES, L. L. Mapeamento de uso e ocupação do solo em uma pequena bacia hidrográfica da Amazônia. Ciência e Natura, v. 39, n. 1, p. 170-178, 2017. Disponível em: <http://dx.doi.org/10.5902/2179460X21737>. doi: $10.5902 / 2179460 \times 21737$

ROMÃO, E. P.; PONTES, A. N.; GUTJAHR, A. L. N.; TORRES, W. R. G. Análise temporal do uso e da cobertura do solo nas áreas desflorestadas do município de Altamira, Pará. Enciclopédia Biosfera, v. 14, n. 25, p. 113-126, 2017. Disponível em: <http://dx.doi.org/ 10.18677/EnciBio_2017A11>. doi: 10.18677/EnciBio_2017A11

SILVA, A. A.; COSTA, D. F. S.; GRIGIO, A. M.; ROCHA, R. M. Análise da paisagem aplicada a caracterização e planejamento ambiental da mata ciliar no trecho urbano do rio Apodi-Mossoró (Mossorpó/RN-Brasil). Boletim Gaúcho de Geografia, v. 42, n. 1, p. 300-318, 2015. Disponível em: <http://seer.ufrgs.br/index.php/bgg/article/view /47141/32950>.

SILVA, E. B.; FERREIRA JÚNIOR, L. G.; ANJOS, A. F.; MIZIARA, F. Análise da distribuição espaço-temporal das pastagens cultivadas no bioma Cerrado entre 1970 e 2006. Interfaces em Desenvolvimento, Agricultura e Sociedade, v. 7, n. 1, p. 174-209, 2013. Disponível em: <https://www.lapig.iesa.ufg.br/lapig/index.php/compo nent/jdownloads/send/4-periodicos/358-analise-da-distribuicao-espaco-temporal-daspastagens-cultivadas-no-bioma-cerrado-entre-1970-e-2006? Itemid=0>.

SILVA, P. R. Os rios paraenses: uma breve descrição potamográfica. Boletim Amazônico de Geografia, Belém/PA, v. 1, n. 2, p. 88-104, 2014. Disponível em: <http://dx.doi.org/10.17552/2358-7040/bag.v1n2p88-104>. doi: 10.17552/2358-7040/ bag.v1n2p88-104

VAEZA, R. F.; OLIVEIRA FILHO, P. C.; MAIA, A. G.; DISPERATI, A. A. Uso e ocupação do solo em bacia hidrográfica urbana a partir de imagens orbitais de alta resolução. Floresta e Ambiente, v. 17, n. 1, p. 23-29, 2010. Disponível em: <http://dx.doi.org/10.4322/floram.2011.003>. doi: 10.4322/floram.2011.003

VAZ, V.; CARVALHO, S. A.; BARBOSA T.; THALES, M. C.; MOURÃO, M.; et al. A pecuária na agenda ambiental da Amazônia brasileira: percepções e representações dos atores locais. In: ALMEIDA, J.; GERHARDT, C.; MAGALHÃES, S. B. (Org.) Contextos rurais e agenda ambiental no Brasil: práticas, políticas, conflitos, interpretações. Belém: Rede de Estudos Rurais, 2012. p. 64-90.

WENCESLAU F. F.; ROCHA J. M. A ferramenta de análise FMEA como suporte para a identificação dos aspectos e impactos ambientais em uma agroindústria de arroz. Tecno-Lógica, v. 16, n. 1, p. 56-66, 2012. Disponível em: <http://dx.doi.org/10.17058/tecnolog.v16i1.2810>. doi: 10.17058/tecnolog.v16i1.2810 